\title{
Role of Social Media Networks in Promoting Hotel Industry Reena Lakha ${ }^{1}$, Prof (Dr) A C Vaid ${ }^{2}$
}

${ }^{1}$ Research Scholar, University School of Management Studies, Rayat Bahra.University, Mohali, Punjab, India. ${ }^{2}$ Rayat Bahra University, Mohali, Punjab, India.

\section{ABSTRACT}

Article Info

Volume 8, Issue 3

Page Number : 40-47

\section{Publication Issue}

May-June-2021

\section{Article History}

Accepted : 01 May 2021

Published : 06 May 2021
In recent years, the hotel industry has started to follow social media marketing strategy as part of its marketing campaign to improve its brand value. Social networking channels are the means a hotel is promoting itself through. There are various channels that the hotels use to communicate with the clients. This paper aims to pick the best channel and use it wisely, so it helps the hotel industry the most. This paper aims to identify the available social media sites for the hotel industry. This study adds new knowledge regarding the hotel's most common social media site. The paper will provide insight into the medium of the social site used for communications and the use of social media advertisements as an integral part of the hotel's marketing strategy.

Keywords : Social Media, Social Media Platforms, Social Networking Sites, Hotel Industry, Hospitality Sector.

\section{INTRODUCTION}

The technology is being updated every minute, and so are the customers' options. Hospitality today has also become customized where everything is just one click away. The days are gone when travelling meant first visiting a place and then searching for a hotel and tourist destinations. Today's traveller checks the details online first and then makes a decision. Holding the pace with the technology and traveller hospitality industry takes the social media approach. In today's world, social media is the main thing. Since the whole world moving on social media, it has opened up a new marketing channel for businesses. This modern method has been embraced in a very positive way by the hospitality industry over the last few years. Nearly every five-star hotel in India now has a presence on social networking platforms and has used it as an eminent part of its marketing strategy.

Social networking networks such as Facebook and Twitter have revolutionized in the last few years, not only how persons communicate with each other but also how companies connect with customers. Hotels and companies in the hospitality sector need to better understand how to deliver their messages through social media platforms to succeed in the business world today. One of the benefits of social media advertisements is that it can be considered that the 
source of the advertisement is a relative of a customer rather than the firm itself. For instance, many hotels and airlines keep a Facebook page. If a friend of yours "likes" the Facebook page of a hotel, it's like a personal recommendation that comes from a trusted source. Best of all, this very successful form of advertisement costs just about nothing for a company.

Several hospitality companies have started offering promotions and exclusive offers to clients through social media platforms. By rewarding consumers for connecting their social media accounts to their companies, hotels and airlines allow them to continue offering free ads on social media platforms and creating customer loyalty for their brand.

\section{SOCIAL MEDIA \& SOCIAL MEDIA MARKETING}

Oxford dictionary describes social media as websites and applications that allow users to create and distribute content or engage in social networking [1].

Through Social media marketing marketers can generate highly targeted traffic while allowing you to connect with your visitors. Cambridge dictionaries describe social media marketing as methods for advertising products, services or brands that use the Internet by attracting the attention of groups of people who discuss them, making comments about them, etc. This research aims to analyze in-depth the methods used by hotels for their marketing and visibility on social media. In the customer-centric industry, such as the hotel industry, marketing plays a very crucial role. The hotels need to be very up-todate with the latest trends. The hotels today are very customer-focused. They take the time to interact with the clients, to understand them, and to provide them with the experience they expect. Also, the feedback is now not only taken on a piece of paper, and the whole conversation has now gone online. Hotels have used social media marketing as a core part of their marketing plan in order to meet the pace of the consumer and competition today [2].

Oxford dictionary describes social media as websites and applications that allow users to create and distribute content or engage in social networking. Cambridge dictionaries describe social media marketing as methods for promoting goods, services, or brands using the Internet by gaining the attention of groups of people who are discussing them, making comments about them online, etc.

Social media, in a few words, are sites powered by continuously updated and fresh content and fed by users as opposed to structured publishers. They consider three types of sites in social media: -1) the website of companies, which contains all the basic information regarding the company, its past, function, etc., 2) the social networking sites, such as Facebook, Twitter, Instagram, etc., where consumers communicate in an informal manner. 3) Review sites - such as Tripadvisor, Four Square etc., where consumers provide reviews on their experience with different hotels and services. It is the entirely hotel's decision to use the different mediums available for contact [3].

\section{LITERATURE REVIEW}

Most hospitality companies use social media platforms to enhance and tailor their customer experience. In the meantime, hotels in Hyatt and Hilton use Twitter as a virtual concierge service that allows guests to "tweet" questions and request answers within the hour. Also, Twitter allows hotel staff to start interactions with guests; even a tweet that is as simple as "Hope you're enjoying your stay!" may provide a personalized touch that some guests really like. One of the greatest impacts social media has had is the rising value and volume of customer feedback. Although a favourable review can attract sales, a negative assessment will scare consumers away just as 
easily. Savvy hospitality enterprises appoint at least one staff member to track blogs and social media sites and respond when appropriate. Industry web sites suggest answering negative feedback by thanking the users, apologizing, describing the measures taken to resolve the issues and preventing the sign of defensiveness.

Blackshaw (2006) defines social media as internetbased applications which carry content created by consumers that is relevant to past experiences or to any source or online knowledge issues. Consumers build this themselves, based on their product and service experience, and share it with each other to inform about the goods and services (Xiang \& Gretzel, 2009). This can be seen as word of mouth (WOM) extension, a very effective mechanism that affects consumer behaviours.

The 21st century is experiencing an explosion of Internet-based messages that are being exchanged via social media. Such media have been a significant force in shaping various aspects of consumer behaviour, from perception to actions after purchase (Mangold \& Faulds, 2009). The marketing patterns have now shifted, and customers can now even interact with other customers using social media instead of businesses talking to their consumers. Many customers already see social media as the most credible source of product and service knowledge than corporate-derived communications.

These are different forms of social networking sites, such as Facebook.com, MySpace.com, Twitter.com; travel review sites, such as tripadvisor.com, lonelyplanet.com; and business sites such as Linkedin.com. Trip Advisor is one of the popular sites where customers share their experience through reviews, and it has become an assertive WOM communication (Ramsey, 2006). To order to be successful in marketing communication across these networks, marketers need to monitor and improve positive WOM through focusing on relationship management (Payne and Frow 2005).

Consumers who have never been to the destination depend heavily on accepting the knowledge provided by other people through word of mouth and social networking sites on the Web, considering the intangible nature of tourism and hospitality services (Saranow, 2004; Ricci and Wietsma, 2006) Compete Incorporated (2007) reports that the content produced by the user has influenced on online travel more than $\$ 10$ billion annually due to the increased reliability it is considered to have compared with more conventional travel marketing types.

Social networking also acts as a cost-cutter because it is a low-cost tool for interacting and showing insight into the desires, emotions, feelings and behaviours of people, in a way that is more straightforward and effective than using a research company to find out this knowledge ( $\mathrm{Li}$ and Bernoff, 2008). Social networking also has a huge effect on hotels who use them to draw new customers, retain existing ones and increase their online presence as well. They cannot disregard the influence of social networking sites and UGC content, nor their role in the conduct of travel planning (Cox, Burgess, Sellitto and Buultjens, 2009). Hotels are constantly using Facebook and Twitter to publicize new events and deals, as well as keeping consumers up to date. The various types of social media and peer and guest reviews that have proliferated across these platforms are rapidly influencing hotel bookings (Astbury, 2011).

\section{METHODOLOGY}

A Research Design is the grouping of conditions for collecting and analyzing data in a manner that seeks to combine relevance to the research object with the procedural economy. The analysis is a simple descriptive study, defined as attempts to explore and explain a topic while providing further information. 
It is where the work attempts to explain what is happening in more depth, filling in the missing pieces and broadening our understanding. It is also where as much information as possible is collected instead of forecasting or drawing up models to forecast the future-the 'what' and 'how' [4].

A sample of the census was adopted for the report. Because it was census sampling, the whole population was confiscated for the study. Therefore, the random sampling technique was used for selecting the sample components. The primary first-hand data was gathered through interviews with the hotel's emarketing staff. Besides it, there were conversations with the immediate bosses, the marketing department executives. The secondary data was gathered through the profile of the business, the business manuals and the reports of the previous year.

\section{ROLE OF SOCIAL MEDIA CHANNELS IN PROMOTING HOTEL INDUSTRY}

The hotels have started to follow the strategy of social media marketing as part of their marketing campaign to improve their brand value. Social networking channels are the means a hotel is promoting itself through. There are various channels that the hotels use to communicate with the clients. The goal here is to pick the best channel and use it wisely, so it helps the hotel the most [5].

Social networking technology is focused mainly on three mediums - Mobile, Web, Desktop. Social media has emerged as an one of the most significant and influential marketing devices over the last decade. The hospitality sector has also adopted this marketing tool with open hands, and this method is used by almost all hotels irrespective of their star rankings.

Social media has changed the entire hotel marketing scenario; hotels now need to be very cautious in handling guests and, in particular, their complaints because one bad experience can badly ruin their reputations. In the previous study, it was said that the most powerful hotel marketing is the customer's word of mouth, but now, thanks to social media, it is the word of millions of mouths that affects the hotel business. In order to get positive outcomes from such marketing, the adoption of proper and most appropriate social media channels is very important for a hotel property.

\section{SCOPE OF THE STUDY:}

- The study analyses a hotel's most common social media channels.

- The study may also help the hotel understand the value of these channels.

\section{OBJECTIVES OF THE STUDY:}

- To define the hotel's most commonly used social media channels to promote their online business.

- To determine the best usage of social networking sites.

- To give the company ideas for enhancing online visibility and marketing.

\section{CLASSIFICATION OF SOCIAL MEDIA NETWORKS}

Social media platforms are the medium through which the hotel markets itself. There are umpteen numbers of channels being used by the hotel industry to connect to the customers. The challenge is to choose the right social media channel and use it wisely so that it benefits the most to the hotel industry.

The social media networks can be classified into three major categories:

\footnotetext{
$\checkmark \quad$ Official Website or blog

$\checkmark \quad$ Social Media Pages

$\checkmark \quad$ Review Pages/ Partner Channels
} 


\section{- OFFICIAL WEBSITE}

The Social Media platform is the web page where the company presents all the information from beginning history to handling the present day, products, spaces, services. This platform is most respected because it is operated by the organization itself and includes all of the company's comprehensive and latest data. Providing hotel property information to the clients and offering packages and loyalty programs is most useful. Since the consumer of today is more techsavvy and competent, it becomes a challenge for the hotel to continuously update the website as well as blog and respond to the needs of the customer. The hotels have improved a great deal in terms of website details and design to attract the client. They just seek to include all the necessary details for the convenience of the customers on the homepage [6].

The hotel needs to use this medium wisely because the hotel's web page makes a great impression on the current as well as prospective customers mind, thereby affecting the hotel's decision to stay. The website will contain all of the important information on the home page, in particular, that which is useful to the customer. The basic content of a hotel website is rooms, restaurants, banquets, leisure activities, hotel USP, management, awards/accomplishments, local city tourist attractions, feedback choice, booking connection, tariff information. In addition, the hotel property also offered a separate social media option, which includes the hotel's social media presence information. To communicate better with the clients, hotel websites often have a small connection to their presence logo on various social media networks.

\section{- SOCIAL NETWORKING SITES}

Social networking sites are the primary means through which users may communicate on Desktop, Laptop or Mobile devices over the Internet. Facebook, Twitter, Instagram, Pinterest are the most popular sites, and the list is endless. Networking sites have gained enormous popularity among people of all age groups over the last decade. Today life depends on social networking sites; all $24 \times 7$ are hooked to those networks. People share everything online, such as their happiness, sadness, likes, dislikes, experiences, grievances; the influence of such sites is such that even if a sneezing person shares it on a social network.

This route is very profitable for the hotel industry because it is easy to communicate with the customer. Most hotels use Facebook in this channel segment; each hotel has its own Facebook page, Twitter handle, Pinterest, Foursquare and Instagram. Social networking sites provide a simple forum for customer interaction. This is also important for a hotel to act also carefully on the social network because one negative message or offensive language can lead to the loss of not even one but several customers.

Those are open forums where he and she can post the experience on the personal account or page of the hotel if the customer wants to. This method is also very helpful for the company as the hotel can quickly contact its customers about new services, upcoming activities, promotional deals etc. It is one of the simplest and most straightforward ways to communicate with the customer. Due to the advent of social media, communicating with the customer and advertisement was very challenging for the hotel. Such networks have helped hotels create a large base of current as well as future customers. The hotels can easily monitor their popularity through options such as the number of likes, followers, social networking website shares [7].

\section{- REVIEW SITES}

Review sites are websites where people share their experiences in the form of reviews, photos, feedback, etc. In India, popular hotel review sites are Tripadvisor, Trivago etc. Review sites help to increase customer base as now an individual, before travelling checks the place and top hotel reviews on the review 
sites, and then accommodation is further considered. Whoever the person posts a negative remark or criticism, it becomes very important for the hotel to respond to both positive as well as negative comments with tact. The hotel will be professionally attentive to every and every query. This channel, if managed correctly, proves to be the channel that makes the hotel business expand [8].

Look at each social media platform to figure out which one is going to work best for your company. Consider the following critical considerations in each of them: the product or service you are providing and the human and financial resources available to you. Can social media be free but think about the worth of your time? Don't sign up for every channel on social media because they're new or famous on the block. Determine which one is most important to your enterprise. Be excellent at one or two channels instead of at five or six on average. Execute an easy and implementable plan before deciding on which social media platform to participate in.

\section{- Treat TripAdvisor like every other Site for Social Media.}

TripAdvisor is often included in the Social Media strategy of any hospitality company. It's a big source of knowledge and understanding for your future guests, as many hoteliers know it. TripAdvisor rates hotels based on three factors: reviews recently reported, the number of reviews and the quality of reviews. At times, persuading your guests to interact and rate your hotel (unless the rate is negative) may seem hard. Trends suggest that people are more likely to post about a negative experience than a positive one, but our team has placed a program in place to deal with the quantity and frequency of guest reviews. We've created review cards featuring Google and TripAdvisor and send them to each of our hotel teams to give guests, hoping they'll be inspired to write on-site about their experience. Ultimately, the key quality to which we adhere is to ensure regularly that all general hotel marketing managers are aware of any and all comments - particularly those less favourable. It is one of the most valuable devices available to us for enhancing our hotel and guest service.

\section{CONCLUSION \& SUGGESIONS}

The amazing thing about social media is that it offers the ideal forum for directly communicating the brand to consumers. With a smart combination of the above-mentioned tricks, we can target our specific audiences with targeted ads to their mobile phones, develop close relationships by reacting to their posts on Facebook and Twitter, and generate the following via our events page. It's a very personalized and strong relationship with customers that builds trust in our brand and service. Hotels should take this even further and invest in a mobile app. What better way to create long-lasting consumer relationships than a direct contact channel between the two of you?

Approximately $\$ 8.0$ billion (an improvement of $6.5 \%$ from last year's figures), direct booking via mobile devices is becoming a major factor in the financial sheets of hotels. While not purely a Social Media Platform, having an effective and well-managed website is becoming a fundamental requirement for any property that wants to stay profitable and competitive, after all, the website is the strongest and most direct resource for shaping its online presence, and if done properly, it can easily become the key driving force behind most reservations. But for now, the industry needs to realize that in a technologically driven world, people are becoming far more autonomous; hotels need to comply and make sure that they, too, make an effort to create direct online booking channels for their internet-savvy clients. It's going to become really important for hotels to have a well-managed website, learn Facebook, Twitter, and think to consider at least about a smartphone app. 
A hotel must use a mixture of these channels as reliance on one would lead to a loss in the future as a major customer base would remain unchanged via that process. The other thing to remember is the knowledge that is to be floated on each portal. Different and appropriate information should be given on various websites; if all have the same comprehensive details, it will result in a lack of interest in the point of customers and thus affect the hotel's company. The third thing to keep in mind is the contact that needs to be made with the customer. Maintaining a constant interaction with the customer, both present and future, is very critical for the hotel because this contact via social media can create an impact on many hundreds of clients. An essential thing to note here is that the property should recognize and select the channel to be adopted carefully and make good use of it. Social media may have both a positive and negative effect on five-star luxury hotels as well as smaller businesses. Actions are an important and prompt response to reexaminations when they are real will result in a big payout. This becomes relevant when it comes to brand identity. Many companies in the hospitality sector beneficially used social media. If the comments were positive or negative, they reacted nicely to their advantage. With rapidly evolving technology, any hospitality operator cannot disregard social media. It should also be borne in mind that it is only the beginning, and nobody knows where it will take us. It is one of the fields where the ideas and hypotheses need to be based and developed, which will help the increasingly rising hospitality industry.

\section{FUTURE RESEARCH AND LIMITATIONS}

Although the current study has made several essential contributions and used a unique research methodological design, however, any study is not without its limitations, which could be addressed in future research. From the above study, it is understood that a great deal of interest has been gained in the marketing of hotels in social media marketing, and more specifically, that social media outlets support and use them extensively. The most popular and influential platforms available are Websites, Facebook, Twitter Accounts, Tripadvisor, Pinterest. It means the researcher does not try to capture all social media platforms and their positive and negative use in the hotel industry. Future research might try to do empirically test the relationship between the current marketing approach and more traditional market approaches that conceptualize social media platform engagement in terms of the performance of the hotel industry.

Future research might test whether such digital marketing strategies are more beneficial as compared to traditional marketing strategies of the hotel industry. Furthermore, it might be interesting to focus on the receiver context, i.e., end-users; for instance, engagement might differ between situations in which individual use a social media platform in a passive (only reading or browsing) versus an active way (e.g., commenting, posting sharing), and it may also differ across the type of device used to access these platforms. Notwithstanding the limitations of the current study, the researcher hopes that our article has made a contribution to better theories on digital platform engagement with advertising. Because the general conclusion is that there is no such thing as "social media," we hope that future research also continues to directly compare different social media platforms.

\section{REFERENCES}

[1]. https://www.nextbigbrand.in/5-popular-socialmedia-networks-in-india-according-to-userbase/

[2]. Billy Bai and et al., "Hotel social media marketing: a study on message strategy and its 
effectiveness," Journal of Hospitality and Tourism Technology, July 2017

[3]. Nicholas Nicoli, "TripAdvisor and reputation: a case study of the hotel industry in Cyprus", EuroMed Journal of Business, July 2017

[4]. https://www.hospitalitynet.org/opinion/407814 4.html

[5]. John O'Neill, "Hotel Brand Strategy", EuroMed Journal of Business, July 2017

[6]. https://go.reviewpro.com/s/article/Introduction -to-Online-Reputation-Management-ORM

[7]. https://www.resnetworld.com/en/onlinereputation-management-orm/

[8]. https://blog.grade.us/hospitality-industryreview-management/

[9]. Inder Singh, "A Review Paper on Hotel Industry-A Study of Trend in Hospitality Industry and the Types of Hotels", International Research Journal of Engineering and Technology (IRJET), Volume: 06 Issue: 03, Mar 2019.

[10]. https://www.reputationsciences.com/orm-forhotel-management/

[11]. https://birdeye.com/blog/hotel-review-sites/

[12]. Markus Schuckert, "Hospitality and Tourism Online Reviews: Recent Trends and Future Directions", Volume: 06 Issue: Journal of Travel \& Tourism Marketing 32(5):608-621, July 2015

[13]. Rob Law and et al., "The influence of online reviews to online hotel booking intentions", International Journal of Contemporary Hospitality Management, 27(6):1343-1364, August 2015.

[14]. https://www.pewresearch.org/facttank/2019/09/09/us-generations-technology-use

\section{Cite this article as :}

Reena Lakha, Prof (Dr) A C Vaid, "Role of Social Media Networks in Promoting Hotel Industry", International Journal of Scientific Research in Science and Technology (IJSRST), Online ISSN : 2395-602X, Print ISSN : 2395-6011, Volume 8 Issue 3, pp. 40-47, May-June 2021. Available at doi : https://doi.org/10.32628/IJSRST218312 Journal URL : https://ijsrst.com/IJSRST218312 